\title{
Explore the evolution and development trends of Folk sports in the city
}

\author{
Qing WANG \\ Zhao Tong Uninversity \\ Zhaotong,657000,China
}

\author{
Chengmin ZHU \\ Zhao Tong Uninversity \\ Zhaotong,657000,China
}

\begin{abstract}
Though its definition is controversial ,the consensus can be reach that Folk sports is one kind of China's traditional national sport in some ways .The following article analyzes the concept and features of folk sports, summing up the evolution of folk sports in the city, the final analysis is about folk sports development trends in the city.
\end{abstract}

Keywords-Development trends; evolution; city; Folk Sports

\section{INTRODUCTION}

The appearance of sport makes the whole society associated, and sports are mainly spread relying on the folklore. Therefore, more and more people pay attention to the subject. The development of the city, not only is related to the development of human civilization, but also related to production, dissemination and diffusion of the human material and spiritual wealth. Research and inquiry of development trends about folk sports in the city, not only can reflect the city's development status, but also will reflect the development process in folk sports, providing a favorable basis for guiding its future development.

\section{ANALYZE THE CONCEPT OF FOLK SPORTS}

Folk sports are a hot point raised in recent years in our country, and discussion of the concept is very intense. Guo Xiaofeng think folk sports are a universal model in sports culture. While Zhang Luya believes that folk sport is a sport in folk activities. Yu Wanyu believes that folk sports are an activity form which depends on folk festival and spread in the folk activities. Cai Zongxin in Taiwanese thinks folk sports are a long-term exercise habit which the nation creates in living place. Tu Chuanfei believes folk sports are not only a kind of sport culture, but also the life and culture. Thus, there is no a unified understanding on folk sports in the current society, but three points are basically the same, first: folk sports and activities were produced in accordance with folk life ; second: folk sports are prevalent in general population; third: folk Sports not only has all the features of sports, but also includes corresponding cultural connotation. Therefore, folk sports which is generated through folk activities and life, is a physical activity enjoyed by residents and heritage in the respective areas. It can not only inherit and develop through festivals, but also exists in people's lives.

\section{ANALYZE THE FEATURES AND FUNCTIONS OF FOLK SPORTS}

\section{A. Characteristics of Folk Sports}

$\mathrm{Yu}$ Wanyu think the national sport is characterized by mass, compatibility, inheritance, nationality and scalability. $\mathrm{Tu}$ Chuanfei believes folk sports characteristics can be divided into internal features and external features, its interior features including the competitive, dependent, entertainment and ethnic differences and human commonality, and external features including regional, historical, variation, ornamental and inheritance. Li Hongmei thinks folk sports is characterized by folk tradition, informal, public, regional, entertainment, universality, heritage, educational nature and fitness and more. Therefore, folk sports first possess national character features, which is produced in the Folk Phenomena and their own as well as with fitness and ornamental characteristics.

\section{B. Function of folk sports}

Guan Zhongwei thinks there are three main functions about folk sports: Self - entertainment and making the society harmonious; carrying on the fine cultural traditions; culturing and promoting identity and the spirit of the Chinese nation. Chen $\mathrm{Li}$ considers the national sport function contains three main points: First, suitable for existing cultural city, it has a mass base; second it is suitable for China's basic national conditions with economic function; the third is the educational function; fourth is a unique fitness function, increasing the number of sports population, promote fitness of the entire nation. Li Yanru thinks folk sports has four main functions: making the cultural life of modern society active; enriching cultural connotation of the sport; promoting Chinese traditional culture communication; bringing physical health, mental and physical recreation, and improving people's mental and health conditions .

Therefore, folk sports is both part of the sport, but it is also the sociological, the main source of folk culture of life, which makes folk sports not only containing the function of sport, but also the function of folk. Its main functions are in the following areas:

Educational function: By participating in folk activities, it can inspire people fighting spirit in mind, and also enhance people's folk culture, for the promotion of cultural exchanges conducted;

Fitness function: It brings physical fitness, mental and physical recreation, and it promotes and improves people's mental health status; 
Promoting individual socialization: By participating in folk sports activities, people can improve basic living skills, teaching social norms and interpersonal relationships are strengthened.

\section{ANALYSIS OF FOLK SPORTS DEVELOPMENT PROCESS IN THE CITY}

For city folk sports development process, the analysis is divided into three stages: the ancient city's development; the development of the modern city and modern urban development.

\section{A. Development of folk sports cities in the ancient stage}

In the historical period, the sport is generated by the human in the labor process, and in its infancy, the main forms of education have the original, the original military training, and the original or primitive recreation medical activities and so on. In the Western Zhou period, there has been a systematic music and dance, making the national sport further improved. With the continuous development of social economy, in spring and Autumn and the Warring States Periods, the city has been rapidly expanded and prospered, making the emergence of cultural and recreational activities as well as a variety of games and activities wholesome life in some people. Outings were relatively popular with people; and subsequently swing and fly kite (also known as kite) appeared.

To the Eastern Han Dynasty, the initial formation of races, the fifth day of May each year, people ate dumplings, held dragon boat races, and in the Qin and Han Three Kingdoms period, the pattern has been formed. Finally, the Qing Dynasty, dragon and lion dances and other activities skipping or spinning top were popular, and also became the peak of a folk sports development .Projects continued to increase, making participation more than in any previous period, which reflects prosperity and development of the period. Continuous development of the economy and businesses, makes our city improved, fully creates a good foundation for the folk sports activities, and meets for urban residents' material and spiritual civilization demand.

\section{B. Development of Folk Sports in modern cities}

Urban development, not only improves the people's living standards, but also promotes the development of sports. From the May fourth movement to the early 1930s, the folk sports has not only been developed, but also been consolidated and promoted. In 1932, the Ministry of Education made clear to the national sports regulations, and in the annual sports festival, it is necessary to give priority to shuttlecock, kites and skipping. Subsequently, folk sports activities have also been organized in many places, and lion dance, dragon, stilts and sandbags and other items are brought into the folk sports. The competitive nature of sports folk is strengthened, and becomes more standardized, which enriches the masses life, and meets their spiritual needs.

\section{Development of Folk Sports in modern cities}

After the founding of new China, the whole national people rejoiced and cheered enthusiastically. Whether it is before or after the reform and opening up, folk sports has been developed rapidly, added to playing top, swing and jumping bamboo and other folk sports activities and games, so the rules of the corresponding activities carried out improve and strengthen development of its times and operability, which lays a foundation for the development of the city folk sports. And in the development period of folk sports, folk sports also went into the community and neighborhood school classroom, making its way to not only rely on their festivals heritage, but also in the school gained popularity. The rapid development of the city gives new vigor and vitality to the folk sports. School, as the cradle of sports and cultural spreading, it is not only the main way to scientific and standardized sport, but also the popularity of a sport must pass.

The introduction of folk sports in school not only complements and promotes the development of school sports, but also raise the students' exercise consciousness, to develop their lifelong interest in sports. For example, in certain primary school in Hubei Province, the dragon and lion dances have been as college physical education curriculum content, and teachers also write the corresponding school-based teaching materials, so that students can be interested in exercise.

In a primary school in Shijiazhuang, Hebei Province, the school sports also was reformed. The bamboo dance, chess, checkers and chess and tai chi fan are introduced into the classroom, all the teachers and the students master these activities, and also hold the races among grade or class regularly, so that students on the basis of folk sports popular among students, students can cultivate team spirit. In this way students can find interest and pleasure from folk sports. In the contemporary life of residents, the main way that they know about folk sports is through television and radio, newspapers, magazines, Internet, and friends' introduction followed.

\section{ANALYSIS OF THE DEVELOPMENT TREND OF FOLK SPORTS IN THE CITY}

Whether folk sports starting from scratch, or from the embryonic stage to the popularity, has experienced several years of development, now it has received public attention and favor, through the analysis of the folk sports development process in the city, we can predict the development trend of folk sports in the city.

\section{A. Achieve the transformation from traditional to fashion}

Its heritage makes it traditional, that is to say there is relatively a long history about folk sports. Meanwhile the inherited project also has an impact of modern society. However, in the continuous development of society, the level of development of the city has also been improved, making the folk culture and traditional folk forms with ultra popular and fashionable characteristics transformed. For example, 
sports festival or Younger festival held in the country or in the school, part of which is through acceptance of residents formed a new folk, while the other part is dying because of the lack of public participation. In order to meet the needs of the people ,Folk sports should first adapt to the development trend of the contemporary society, not only to retains the traditional things, but not separates from the modern society, and thus become a creature that just holds a superficial appearance.

\section{B. Achieve ethnic and regional restructured and reproduced}

With the continuous development of China's economy and society, the ethnic and regional of folk sports have undergone weakening. With the continuous advancement of modern media technology, the folk sports not only exists in the local folklore, and also be restructured in the lives of the residents. Therefore, in order to meet the needs of social development and the people, first and foremost we must achieve cross-regional and cross- nation folk sports.

\section{C. achieve the combination of competitive nature and public nature}

Populace is the main source of folk sports, and people's favor is the source of folk sports existence. After several centuries of spread, folk sports is loved and welcomed by people in many places. The competitive nature in today's sport is an important feature, with honors and race victory as the goal to compete physical and psychological qualities of the people involved. Therefore, the folk sports fitness and recreation has received a majority of the nation's favorite, and if the competitive nature can be combined with the general public, it will not only promote the development of the advantages of folk sports, but also can improve their competitive level, thus promoting the folk sports popularization and development.

\section{CONCLUSIONS}

From the above analysis and inquiry, we can conclude that the folk sport which contains all the characteristics of sport and folklore is broadcasted by the folk life and activities. In order to adapt to social and economic development, it reflects the individual promoting function of education, health and culture. Urban development in the future is very optimistic. With urban living standards improved, people will demand for higher quality of life and the spirit, and development of folk sports exactly conform to the needs of all urban residents. It brings physical fitness, mental and physical recreation. In today's cities, folk sports has been gradually recognized by the residents, and the population participated will increase, which finally enhance the heritage and development of folk sports.

\section{References:}

[1] Shen Liling. Primary and secondary school curriculum resources in Jiangxi Folk Sports Development Status and Development Strategies[D]. Jiangxi Normal University, 2005.

[2] Tang Lihui. Our National Traditional Sports tiered evaluation system and development strategy research [D]. Shanghai Institute of Physical Education, 2011.

[3] Liu Jiexian. The Status Quo folk sports development in rural social change under the new background [D]. Guangxi University for Nationalities, 2013.

[4] Chen Hongxin. Jiangsu Province rural junior high school physical education and health classes introduce Folk Sports [D]. Soochow University, 2009.

[5] Zhang Chan .Research and Countermeasures to carry City Square national traditional sports in Kunming [D]. Yunnan Normal University, 2008.

[6] Chen Zuxia. Based on fieldwork folk village folk sports rheological evolution theory [D]. Jiangxi Normal University, 2013. 